\title{
OS EXERGAMES E A EDUCAÇÃO FÍSICA ESCOLAR NA CULTURA DIGITAL'
}

\author{
GRAD. ANA FLÁVIA DE OLIVEIRA BARACHO \\ Licenciada em Educação Física pela Universidade Federal dos Vales do Jequitinhonha e Mucuri \\ (UFVJM) (Diamantina - Minas Gerais - Brasil) \\ E-mail: afbaracho@hotmail.com
}

\author{
MS. FERNANDO JOAQUIM GRIPP \\ Mestre em Educação Física pela Escola de Educação Física da \\ Universidade Federal de Minas Gerais (UFMG)
}

Professor do Departamento de Educação Física da Universidade Federal dos Vales do Jequitinhonha e

Mucuri (UFVJM) (Diamantina - Minas Gerais - Brasil)

E-mail: fernando.gripp@ufvjm.edu.br

\section{MS. MÁRCIO ROBERTO DE LIMA}

Mestre em Educação pela Universidade Federal de São João del-Rei (UFSJ), Doutorando em Educação pela Faculdade de Educação da Universidade Federal de Minas Gerais (FAE/UFMG) (Cidade - Estado - País)

Professor do Departamento de Ciências da Educação da Universidade Federal de São João del-Rei

(DECED/UFSJ) (São João del-Rei - Minas Gerais - Brasil)

E-mail: marcinholima@gmail.com

\begin{abstract}
RESUMO
Os exergames são jogos eletrônicos que captam e virtualizam os movimentos reais dos usuários. Com o objetivo de discutir as perspectivas da utilização da virtualidade dos videogames na educação física escolar, participaram deste estudo 117 alunos de uma escola pública, com idade entre 13 e 14 anos. Os voluntários responderam a um questionário para identificar o nível de contato com as tecnologias digitais e, em seguida, relataram suas percepções sobre a vivência em dois jogos, o exergame e o real. Os resultados constataram a imersão dos estudantes na cultura digital e no processo de virtualização que Ihe é típico, assim como apontaram algumas perspectivas de utilização crítica dessa nova linguagem, que pode ampliar e recriar as possibilidades das práticas e vivências corporais.
\end{abstract}

PALAVRAS-CHAVE: Videogame; educação física escolar; jogo; cultura digital.

I. Este trabalho teve o apoio da Fundação de Amparo à Pesquisa do Estado de Minas Gerais - Edital 005/2009 - Programa Institucional de Iniciação Científica e Tecnológica - FAPEMIG/UFVJM. 
O cenário sociotécnico contemporâneo evidencia as telas digitais como referências de produção, consumo, comunicação, lazer, entre outras. Esse fato indica que vivemos num tempo em que a sociedade vem se apropriando das funcionalidades das tecnologias digitais de informação e comunicação, e incorporando-as em suas formas de relacionamento. Assim, esse panorama convergente e de sinergia entre o social e o tecnológico, consolida-se como um novo marco na história da humanidade, onde o "fazer"- e mesmo o "pensar o fazer" - são constantemente reconfigurados mediante a enormidade de possibilidades oferecidas pelos meios virtuais, típicos de uma cultura digital. Esse novo modus operandi social caracteriza o que Lévy (1999) e Lemos (2002) denominam de cibercultura.

A cibercultura caracteriza o surgimento de uma teia global de conexões - que se efetivam via dispositivos de hardware e interfaces - formando em sua totalidade um "espaço-informação", ou o ciberespaço. Nele passou a ser possível, por exemplo, o estabelecimento da troca comunicativa, o acesso remoto à informação e a simulação de diferentes processos. Em outras palavras, um (inter)agente que participa do ciberespaço pode assumir uma identidade digital e, a partir disso, estabelecer (rel)ações nos mais variados campos de conhecimento ali virtualizados. Mais especificamente para o campo das simulações, ressalta-se que a cada ciclo do vertiginoso desenvolvimento das tecnologias digitais, ampliam-se as possibilidades de interação em uma realidade virtual.

A realidade virtual é uma experiência imersiva, interativa, estruturada e apresentada por meio de imagens gráficas geradas em tempo real por computador. Esse conceito ganha força com Rivoltella (2008), que a considera como "um mundo de objetos sintéticos (porque gerados pelo computador) no qual é possível emergir-se", possibilitando interações via dispositivos eletrônicos-digitais. Esse processo interativo mostra-se como uma dinâmica fecunda, potencializadora de realizações e que permite novas formas de criação. Lévy ( 1996) aponta a origem do termo "virtual" no latim virtualis, que é derivante de virtus: força, potência. Partilhamos com esse autor a ideia de que "virtual" - enquanto ausência de existência - não é o oposto do "real" - enquanto presença tangível. Dessa forma, uma entidade virtualizada está sujeita a reconfigurações e atualizações, o que se traduz em complexificações da realidade.

Com o aprimoramento das tecnologias digitais, a realidade virtual passou a ser utilizada amplamente por diferentes segmentos, como no entretenimento, na saúde, nos negócios, em treinamentos e na educação. A partir de suas características básicas - a imersão, a interação e o envolvimento - é possível pensar em sua utilização como meio de ampliação das formas de ensino-aprendizagem. A realidade 
virtual nos possibilita conhecer, visitar, aprender sobre lugares distantes ou mesmo aqueles que não existem mais. É, portanto, um recurso potencializador do espaço da sala de aula tradicional, podendo ser utilizada como uma forma de motivação dos alunos, uma vez que é dotada de alto poder de ilustração, e constitui-se como uma ferramenta educacional que oportuniza diferentes experiências. Permite, também, a análise de situações simuladas, o respeito ao ritmo de aprendizagem dos alunos, a inclusão de pessoas portadoras de necessidades especiais em tarefas diversas, e estimula a participação ativa dos alunos (BRAGA, 200I).

Dentre as possíveis formas de contato com a realidade virtual, destaca-se o universo dos jogos eletrônicos. Surgidos na década de 1960, os videogames tinham como objetivo inicial o entretenimento (REIS; CAVICHIOLLI, 2008), porém, dados recentes mostram que eles vêm se aprimorando e reconfigurando o tempo que antes era dedicado à música, à televisão e ao cinema (CARELLI, 2003). Apresentam-se, dessa forma, como mais uma opção de lazer em nossas vidas, no cenário da cultura digital.

Ao resgatar a história dos videogames, Feres Neto (2007) nos mostra a sua rápida evolução, passando de equipamentos rudimentares de baixa qualidade gráfica até chegar aos dias de hoje, em que grandes empresas disputam um mercado milionário e oferecem produtos que incorporam rapidamente os novos recursos tecnológicos da virtualidade em três dimensões. Como resultado dessa evolução, Costa e Betti (2006) apontam o surgimento dos primeiros "videogamers" ou ciberatletas, jogadores profissionais que chegam a ganhar milhões nos grandes torneios internacionais.

Gee (2009) ressalta que os bons videogames incorporam bons princípios de aprendizagem: identidade, interação, customização, desafio, sentidos contextualizados, pensamento sistemático, exploração, revisão dos objetivos, conhecimento distribuído e outros. $\bigcirc$ autor nos desafia a "tornar a aprendizagem, dentro e fora das escolas, mais parecida com os games, no sentido de que ela use os tipos de princípios de aprendizagem que os jovens vêem todos os dias nos bons videogames", quando jogam de um modo reflexivo e estratégico.

Em 2006, a empresa japonesa Nintendo lançou no mercado o videogame Wii, que alterou de forma significativa a forma de interação do usuário com o jogo. Além de simplesmente apertar botões ou mover as alavancas, o Wii permite aos jogadores controlar o jogo usando o movimento do próprio corpo (SPARKS; CHASE; COUGHLIN, 2009). Foi o primeiro videogame ${ }^{2}$ a trazer esta nova tecnologia de

2. Em dezembro de 2010 a empresa Microsoft lançou no mercado a tecnologia do Kinect para o console Xbox. Essa funcionalidade virtualiza os movimentos corporais dos jogadores, dispensando dispositivos apontadores (controles físicos). 
captação de movimentos humanos de forma comercializável ao mercado (REIS; CAVICHIOLLI, 2008). Essa nova forma de interação tem recebido diferentes denominações, tais como: exergames, exergaming, activity-promoting video games, physically interactive video game, active video gaming, motion-sensing video game, activity promoting computer games, active video games, entre outras Nesse trabalho será usada a expressão exergames (EXG), por ser uma das mais utilizadas na literatura.

Alguns estudos já comprovaram a aplicabilidade dos EXG em programas de reabilitação e promoção da saúde (SILVA; TORRES, 2009; NITZ et al., 20 I0; ANDERSON; ANNETT; BISCHOF, 20I0; DEUTSCH et al., 2008; REIS; CAVICHIOLLI, 2008). Para a educação física, a tecnologia dos EXG também coloca novos desafios e discussões, pois incorpora o ato de "mover-se para jogar", contrariando a ideia do sedentarismo, da passividade e da inatividade do jogador. Ramos (2008) afirma que, dentro desse novo paradigma, o professor tem uma função estratégica quando pensamos na aplicabilidade pedagógica dos jogos eletrônicos e nos reflexos que eles podem ter no desenvolvimento humano. Surge, então, o debate sobre as possibilidades e os obstáculos que possibilitem o diálogo e a incorporação dos jogos virtuais na área da educação física escolar.

Por se tratar de uma tecnologia muito recente, a literatura ainda é escassa. O tema ainda é controverso, conflitante, havendo apenas especulações e dúvidas acerca da utilização dos videogames na educação física escolar. Diante desse quadro, o objetivo desse trabalho é contribuir com uma discussão sobre as potencialidades e perspectivas da utilização da virtualidade, especificamente dos EXG, na educação física escolar, a partir do relato de jovens alunos de uma escola pública, que vivenciaram um determinado jogo nos ambientes real e virtual.

\section{MATERIAIS E MÉTODOS}

Participaram como voluntários desse estudo 117 jovens de ambos os sexos, com idade entre 13 e 14 anos $^{3}$, estudantes de uma escola estadual da rede pública de ensino localizada em um bairro de classe média da cidade de Diamantina-MG. O presente estudo é de caráter descritivo-exploratório e pode ser dividido metodologicamente em duas partes distintas. A primeira buscou identificar e analisar a presença das tecnologias da informação e comunicação (TICs) e o fenômeno da virtualidade no universo cotidiano dos voluntários por meio de um questionário; e a segunda, por meio de uma intervenção prática, buscou analisar a percepção dos

3. O projeto foi previamente aprovado pelo Comitê de Ética na Pesquisa com Seres Humanos da UFVJM sob o protocolo $0 \mathrm{I}$ I/20 I 0 . 
voluntários em contato com uma forma de realidade virtual, especificamente os EXG, seguida da prática do jogo real (no caso o Baseball).

\section{FASE I - QUESTIONÁRIO DE IDENTIFICAÇÃO DA PRESENÇA DAS TICS E DA REALIDADE VIRTUAL NO COTIDIANO DOS ALUNOS}

Nesta fase inicial, os voluntários responderam individualmente, em uma sala de aula, um questionário composto por questões objetivas, para detectar a presença das TICs no cotidiano dos alunos. Também foi levantado o número de horas que os voluntários dedicam ao uso desses equipamentos e o tempo despendido em interações no ciberespaço (jogos eletrônicos, blogs, redes sociais, chat, correio eletrônico e outros). Por último, os voluntários relataram o possível conhecimento e contato com os exergames, especificamente o console Wii da Nintendo.

\section{FASE 2 - VIVÊNCIAS E PERCEPÇÕES DO JOGO VIRTUAL E REAL}

Dos participantes da primeira fase do estudo, foram convidados para a segunda fase do estudo todos os alunos que relataram que nunca tiveram a oportunidade de praticar algum EXG anteriormente. Desse grupo, oito voluntários aceitaram participar da segunda fase e apresentaram o termo de consentimento assinado pelos pais.

Os participantes desta fase tiveram a oportunidade de praticar o jogo de baseball do Wii Sports. Visando assegurar as mesmas condições para todos os voluntários, foi feita uma demonstração básica do funcionamento do jogo aos participantes, mas não foram dadas informações adicionais sobre regras da modalidade e dicas sobre do jogo. A prática foi feita em uma sala reservada da escola, durante o horário extracurricular. Os alunos foram agrupados aleatoriamente e puderam, sob a supervisão da equipe de pesquisa, vivenciar individualmente o jogo no ambiente virtual durante dez minutos.

Após esta prática, os voluntários foram levados para o gramado da escola para a experiência do jogo de Baseball, cujas regras foram adaptadas para facilitar e motivar a prática. Antes do jogo propriamente dito, os voluntários tiveram dez minutos para familiarização de alguns movimentos específicos do jogo. Essa familiarização justifica-se pelo fato dos que os voluntários nunca praticaram esse esporte, que necessita de habilidades motoras específicas, tais como a rebatida de uma bola com um taco. Como medida de segurança, os alunos ficaram a uma distância segura do rebatedor, e foi utilizada uma "bola de meia" como alternativa ao material oficial confeccionado em madeira e couro.

Logo após as experiências com o Baseball nos espaços virtual e real, os voluntários responderam a um questionário com questões abertas, cujo objetivo 
era registrar o relato de suas experiências, analisar a percepção dos alunos com as vivências e levantar a discussão sobre a possibilidade de inserção e utilização dos EXG na educação física escolar. Para isso, foram feitas as seguintes perguntas: $O$ que você achou da prática do jogo no videogame? O que você achou da prática do jogo feito no campo? Que tipo de relação você pode fazer entre as duas experiências (virtual e real)? O que você acha sobre a utilização de exergames na educação física da escola? Além disso, foi deixado espaço para possíveis comentários, sugestões e críticas.

\section{RESULTADOS E DISCUSSÃO}

A Tabela I apresenta o percentual da presença das TICs na residência dos voluntários, e mostra o predomínio dos aparelhos de televisão, celulares e computadores no cotidiano de suas famílias. A rápida disseminação dos computadores pode ser constatada quando comparamos os resultados encontrados no trabalho de Betti ( 1997), quando apenas 3 I\% dos alunos de escolas particulares de São Paulo tinham computadores em casa.

A Tabela 2 apresenta o uso diário das novas tecnologias, com destaque para os computadores e a televisão. Betti (1997) já nos alertava que, em meados da década passada, os adolescentes brasileiros despendiam em média quatro horas diárias diante da TV. Esse posto de liderança parece estar sendo ocupado rapidamente pelo computador, visto que $51,28 \%$ relataram passar mais de quatro horas diárias utilizando esse equipamento.

Tabela I. Frequência relativa (\%) da quantidade dos recursos tecnológicos que os voluntários têm em casa

\begin{tabular}{lllll}
\hline & 0 & 1 & 2 ou mais & Em branco \\
\hline Televisão & 0,00 & 9,40 & 87,18 & 3,42 \\
Videogame & 39,32 & 47,86 & 10,26 & 2,56 \\
Videogame portátil & 83,76 & 11,11 & 0,85 & 4,27 \\
Computador & 6,84 & 78,63 & 14,53 & 0,00 \\
Notebook & 68,38 & 23,08 & 2,56 & 5,98 \\
Celular & 0,00 & 10,26 & 88,89 & 0,85 \\
\hline
\end{tabular}


Tabela 2. Frequência relativa (\%) do tempo de acesso diário aos recursos tecnológicos

\begin{tabular}{lllll}
\hline & Até 30min & 30min a 4h & Mais de 4h & Em branco \\
\hline Televisão & 6,84 & 48,72 & 44,44 & 0,00 \\
Videogame & 36,75 & 35,04 & 17,95 & 10,26 \\
Computador & 6,84 & 37,61 & 51,28 & 4,27 \\
Jogos de Computador & 43,59 & 29,91 & 22,22 & 4,27 \\
Jogos de Celular & 71,79 & 16,24 & 6,84 & 5,13 \\
E-mail & 45,30 & 28,21 & 18,80 & 7,69 \\
Orkut & 15,38 & 38,46 & 37,61 & 8,55 \\
Twitter & 53,85 & 20,51 & 6,84 & 18,80 \\
Blog & 54,70 & 17,09 & 5,98 & 22,22 \\
Bate-papo & 29,06 & 23,08 & 35,04 & 12,82 \\
\hline
\end{tabular}

Os dados da Tabela 2 também nos permitem identificar a forte presença da internet no cotidiano dos voluntários. Destaque especial é dado às redes sociais e aos serviços de bate-papo (chat) on line. Nesse novo espaço de informação e comunicação surgem vários mundos, cada um com sua própria comunidade, com seus próprios habitantes virtuais e a sua própria cultura. Aqui são reforçadas as ideias de Lévy (1999) e Lemos (2002) quanto à apropriação social dos dispositivos digitais para a comunicação, o que reflete as novas formas de relacionamento na cibercultura.

Chama também atenção a presença dos videogames na maioria dos lares (58, 12\%), diante de seu custo e do nível de prioridade de aquisição na família. Outro dado interessante é o que mostra que mais da metade dos voluntários $(52,99 \%)$ relatam sua utilização por pelo menos 30 minutos por dia.

Ao analisarmos esses números, percebemos duas características típicas do ciberespaço: seu dinamismo e flexibilidade. É nessa nova extensão virtual que estão presentes funcionalidades, tais como: o correio eletrônico, os blogs, os comunicadores instantâneos, os ambientes interativos, simuladores e outros. Assim, esse mundo de telas digitais configura-se como passaporte para a interatividade no ciberespaço, não sendo incomum encontrar (inter)agentes com diferentes "janelas" abertas em seus dispositivos de acesso e exploração do virtual.

Surge daí a tríade "televisão-computador-videogame" como importante fonte de comunicação e informação dos jovens atuais, elementos presentes no cotidiano dos alunos e, consequentemente, fator determinante em sua formação e visão de mundo. Assim, pode-se afirmar que as TICs e os ambientes imersivos de realidade virtual estão fortemente presentes no cotidiano dos jovens participantes deste estudo. 
Em relação ao nível de conhecimento e contato dos voluntários com EXG, $77,78 \%$ nunca teve a oportunidade de praticá-lo, mas $66,67 \%$ dos alunos conhecem essa nova tecnologia.

A segunda fase do estudo, na qual os alunos relataram suas percepções sobre as práticas real e virtual do jogo de Baseball, permitiu identificar importantes pontos de discussão sobre as possibilidades de utilização dos EXG na educação física escolar.

Uma das principais críticas associadas ao videogame é a passividade e a inatividade do jogador. Em nosso estudo, os voluntários não relataram cansaço físico na prática virtual, porém encontramos na literatura estudos que comprovam que os EXG contribuem para elevar o nível de atividade física diária dos indivíduos, têm efeitos positivos sobre a saúde, oferecem uma oportunidade para as crianças serem fisicamente ativas no ambiente doméstico, facilitam a prática desportiva em condições climáticas adversas, entre outros benefícios (MIYACHI et al., 20 I 0; GRAVES et al., 20I0; DALEY, 20 I0).

Apesar da comprovada eficiência dos EXG na elevação do gasto energético, os autores afirmam que estes jogos não são substitutos das atividades físicas reais (DALEY, 20I0; LANNINGHAM-FOSTER et al., 2009). Definitivamente, não devemos encarar o virtual como substituto imediato do real (LÉVY, 1999), mas sim um movimento de inovação que - para o caso - expande as possibilidades do movimentar-se.

No que diz respeito à prática do jogo no espaço real, os entrevistados demonstraram um interesse relativo, porém a mesma foi qualificada como muito "cansativa" e de baixo êxito nas jogadas: "Eu gostei, apesar de não ter acertado nenhuma bola"; "Foi bom só que é cansativo e tem que ficar no sol"; "Foi legal, mas é um pouco cansativo", "Muito difícil e cansativo, mais do que eu imaginava."; "Muito bom, mas cansativo". Em relação à prática virtual do jogo, foi constada uma visão diferente. A maioria respondeu que a prática virtual é muito divertida, original e diferente do habitual. Pelos relatos dos alunos é possível identificar um envolvimento positivo com esta atividade: "Foi legal ter feito algo que nunca havia feito"; "Muito divertido"; "Achei muito interessante a tecnologia, além de se divertir faz bem para o corpo"; "Achei muito legal"; "Eu achei o jogo super legal".

Segundo Kenski (1995), "o esporte virtual, praticado nos videogames e terminais de computador, faz parte de outra realidade, mais veloz, mais bonita, mais atraente e com maior chance de sucesso do que a dura realidade concreta da prática esportiva." A autora também afirma que "os softwares com competições esportivas garantem, aos seus jogadores, emoções similares às vividas concretamente". Neste novo espaço, o "atleta virtual está dentro da arena, no cenário da partida, e o seu desempenho será acompanhado e pontuado. No mundo virtual o usuário pode 
alcançar a vitória, quebrar recorde, subir ao pódio e receber medalhas virtuais". É muito importante destacar que, talvez, esteja aí um possível caminho para a Educação Física recuperar o interesse dos alunos que não gostam de esportes ou não participam das aulas regularmente. Este aspecto pode ser constatado pela fala dos voluntários: "Na virtual eu senti mais emoção na hora de jogar e na real não." "No virtual dá pra se imaginar dentro de um campo de baseball." "A virtual é melhor, me ajudou a jogar a real, pois se não tivesse jogado a virtual teria dificuldade na real." "As duas necessitam do movimento dos braços, é como se fosse a mesma coisa jogar virtualmente e realmente, a única diferença que achei é que lançar virtualmente parece ser mais fácil."

Daley (20 I0) afirma que os EXG podem proporcionar oportunidades para as crianças aprimorarem seu controle motor e competências em um ambiente "não ameaçador", o que pode ser particularmente verdadeiro para crianças que têm problemas funcionais e/ou de coordenaçãa, os quais dificultam a sua participação nos jogos tradicionais com outras crianças. "Os jogos oferecem um ambiente de ensino-aprendizagem agradável, motivador e enriquecido, onde a criança poderá desenvolver-se pessoal e socialmente de forma integral e harmoniosa" (ROSADO, 2006).

Além disso, com a garantia legal da inclusão de pessoas com deficiência nas escolas regulares, os EXG se configuram como uma possível estratégia de auxílio aos professores de educação física, que muitas vezes têm dificuldades de envolver tais alunos. A virtualização corpóreo-motriz e o estímulo à interatividade proporcionada pelos EXG permitem que esses alunos possam experimentar as sensações e emoções típicas do jogo (DEUTSCH et al., 2008; ANDERSON; ANNETT; BISCHOF, $2010)$. Esse aspecto foi citado por uma das voluntárias: "Eu achei o jogo super legal, e interessante por que pessoas que não têm condições de andar poderiam praticar esse tipo de esporte, e este esporte serve como uma fisioterapia."

Apesar das potencialidades relatadas acima, os EXG apresentam algumas desvantagens. $O$ uso inadequado e sem orientação apropriada deste equipamento pode trazer riscos aos seus usuários. Sparks, Chase e Coughlin (2009) analisaram 39 casos de lesões em decorrência do uso dos EXG, e concluíram que essas lesões são mais prováveis de acontecer em jogadores não familiarizados ou que subestimam a tecnologia dos EXG, e sugerem que, com o aumento da popularidade desses jogos, os profissionais da área da saúde devem estar preparados para tratar desses novos casos.

Outro grande problema advindo da utilização inadequada dos EXG é a dependência e o uso abusivo dos jogos eletrônicos, que causam sérios prejuízos na vida profissional, escolar, social e familiar. Nesses casos, o uso sadio e adaptativo do jogo eletrônico é substituído pelo abuso e pela falta de controle, que causam severos transtornos na vida cotidiana dos usuários (ABREU et al., 2008). 
Diante das vivências destacadas neste estudo, o profissional de educação física vê-se diante de novos desafios, onde deve tentar maximizar as vantagens da utilização dos EXG e minimizar suas desvantagens. À primeira vista, e de forma reducionista, imagina-se que há o risco da máquina ocupar o lugar do profissional de educação física ou levar à mecanização e estereotipação dos movimentos dos alunos. Outros, porém, encaram a aplicação da virtualidade como ferramenta de apoio para a área. Feres Neto (200 I, p. 87), afirma que

[...] cabe à educação/educação física uma ação que possibilite a elevação dos níveis de participação, quer na prática ou na assistência. Para tanto, penso ser fundamental a não separabilidade entre estes dois gêneros de conhecimento nas aulas de educação física, de modo a levar em conta o virtual e o atual do movimento, na medida em que, como já vimos, o esporte telespetáculo, o videogame e os esportes radicais tornam mais complexas as esferas vivenciais entre o assistir e o praticar.

Nesta perspectiva, os EXG podem contribuir para a educação física escolar de uma forma direta na motivação e na participação dos alunos nas aulas, pois, segundo Alves (2007), alguns fatores desmotivam a prática da educação física, tais como o relacionamento professor-aluno, a metodologia de ensino e os conteúdos, que acabam se concentrando nos esportes coletivos. E é neste ponto que se percebe a motivação dos alunos habilidosos e a fuga dos menos habilidosos. Muitos queixam-se também do cansaço trazido pela prática de exercícios físicos, como percebemos na maioria das respostas do questionário de relato de vivência. Os EXG podem trazer para as aulas de educação física práticas diferentes, conteúdos diversificados, esportes inabituais, formas divertidas e motivadoras de se abordar os temas nos ambientes educacionais. Além disso, podem oferecer às crianças a oportunidade de experimentar uma maior diversidade de atividades, às quais podem não ter sido expostas de outra forma durante suas vidas. Isto pode conduzir, posteriormente, para aumentar a sua motivação para se envolverem nestas atividades, em clubes desportivos locais ou dentro de suas comunidades (DALEY, 20I0). Esse aspecto pode ser constatado nas respostas dadas pelos participantes deste estudo em relação à utilização dos EXG na educação física escolar: "esses movimentos na escola ajudam bastante no aprendizado e ajudam o corpo em vários movimentos." "Legal por causa dos alunos aprenderem jogos novos e diferentes na escola." "Seria perfeito. Porque iria fazer uma experiência legal na escola." "Perfeito, é sempre bom ter uma coisa diferente na escola." "Eu acho que seria bem melhor, que os jogos reais, porque eu gosto mais de jogos eletrônicos."

Neste novo cenário, o professor seria o elo entre a experiência do jogo dentro e fora da virtualidade. Segundo Kenski (1995), as vivências virtuais contribuem de forma 
agradável para a aprendizagem, e o professor assume uma importante configuração no processo, provocando a troca de saberes e a interatividade entre os alunos.

Para esta utilização dos jogos eletrônicos na educação física, Feres Neto (200 I , 2007) traz a proposta de "mixagem" e "estéreo" de Babin e Koulomdjian ( 1989). Em um primeiro momento aplica-se a mixagem, na qual os jogos eletrônicos auxiliariam o professor nas aulas de educação física, contribuindo na aprendizagem de técnicas de movimento. Em seguida, o estéreo, em que os jogos eletrônicos seriam os objetos de estudos, criando espaços de discussão e trazendo a criticidade aos alunos, que poderão passar de meros jogadores passivos a sujeitos críticos e conscientes.

Azevedo, Pires e Silva (2007, p. 98) afirmam que essa estratégia também é citada por outros autores (FERES NETO, 2005, 2007; MOITA, 2004, 2006, 2007a, 2007b; MARTINS, COUTO JUNIOR, 2007), e acrescentam:

[...] a escola parece ser o local adequado para a apropriação esclarecida e criativa dos JE's ${ }^{4}$, inserindo assim uma das atividades preferidas dos jovens em seu currículo, ao invés de permanecer distante das suas realidades, aproveitando o seu potencial educativo. Através da mediação dos professores, num primeiro momento, os JE's poderiam ser utilizados para abordar os diversos conteúdos das disciplinas sendo jogados pelos alunos; num segundo momento, os professores e os alunos poderiam discutir as características e os valores vinculados a estes jogos, como os seus diversos gêneros, as diversas formas de serem jogados, seus preconceitos e estereótipos.

Para a proposta de inserção dos EXG na Educação Física, acredita-se que existem alguns limites a serem superados, conforme Feres Neto (2007), Vaghetti e Botelho (20 I 0), e Azevedo (2008): a falta de recursos financeiros da escola; a mentalidade dos agentes envolvidos; a desvalorização do lúdico nas atividades escolares em prol das dimensões mais técnicas da informática na escola; o anacronismo da escola em relação às novas tecnologias e, consequentemente, com as necessidades de seus alunos; os diferentes tempos da escola e dos jogos eletrônicos; a capacidade ou falta de formação dos professores para o uso das novas tecnologias, para o pleno aproveitamento da mesma. Os obstáculos e desafios são muitos, mas é preciso que os profissionais de educação física iniciem essa discussão, que a educação física se posicione frente a esse novo paradigma, e que se reconfigurem diante dessa nova cultura digital.

\section{CONSIDERAÇÕES FINAIS}

Reconhecendo as limitações de um estudo descritivo-exploratório, e não negligenciando o indispensável cuidado em relativizar os depoimentos dos sujeitos

4. JE's: jogos eletrônicos 
participantes, o presente trabalho nos permite identificar alguns pontos que merecem reflexão por parte dos profissionais de educação física, independente de sua área de atuação.

A partir dos dados encontrados e os relatos dos voluntários, corroborados pela recente literatura, constatamos que as TICs e os ambientes imersivos de realidade virtual estão fortemente presentes no cotidiano dos jovens participantes deste estudo. Parece-nos, então, que a cultura digital é uma via inevitável, um caminho a ser percorrido pela atual e futuras gerações. Esse novo cenário demanda um professor aberto ao novo, capaz de dialogar e transitar na cultura digital; que seja capaz de absorver e potencializar os benefícios das tecnologias digitais e virtuais como elementos presentes no processo de ensino-aprendizagem.

O professor de educação física precisa estar preparado para se relacionar e dialogar com os alunos que emergem com essa nova cultura. Porém, é indispensável manter visão crítica sobre o uso das tecnologias digitais, não considerando o virtual como substituto imediato do real, mas sim como um desafio de incorporação de uma nova linguagem, que amplia e recria as possibilidades das práticas corporais na cibercultura.

Os videogames, ícones da cultura digital, quando jogados de forma reflexiva e estratégica, incorporam bons princípios, capazes de dinamizar a reconfiguração do ensino-aprendizagem às exigências da cibercultura. Além disso, para a educação física, os EXG assumem um significado diferente ao incorporar o "mover-se para jogar", rompendo o paradigma da inatividade dos jogos eletrônicos e criando novas possibilidades de vivências corporais.

Exergames and the school physical education in the digital culture

ABSTRACT: The exergames are electronic games that capture and virtualize the real movements of the users. With the aim of discussing the perspectives of using virtual videogames in school physical education, I I 7 students participated in this study at a public school aged I3 and I 4. The subjects answered a questionnaire to identify the level of contact with digital technologies, and then reported their perceptions about the experience in two games, the exergame and the real. The results showed the students' immersion in the digital culture and in the process of virtualization which is typical, as pointed out some critical perspectives of using this new language that can expand and rebuild the possibilities of bodily practices and experiences.

KEYWORDS: Videogame; Physical Education; Game; Digital Culture

\section{Exergames y la educación física escolar en la cultura digital}

RESUMEN: Exergames son juegos electrónicos que capturan y virtualizan los movimientos reales de los usuarios. Con el objetivo de discutir las perspectivas de utilización de la virtualidad en la educación física escolar, I I 7 estudiantes entre 13 y 14 años de un colegio 
público participaron en este estudio. Los sujetos respondieron a un cuestionario para identificar el nivel de contacto con las tecnologías digitales, y informaron sus percepciones acerca de la experiencia en dos juegos, exergame y real. Los resultados mostraron la inmersión de los estudiantes en la cultura digital y el proceso de virtualización que le és típico, como se ha señalado algunas perspectivas críticas de la utilización de este lenguaje que puede ampliar y reconstruir las posibilidades de las prácticas corporales.

PALABRAS CLAVE: Videogame; educación física escolar; juego; cultura digital

\section{REFERÊNCIAS}

ABREU, C. N. et al. Dependência de Internet e de jogos eletrônicos: uma revisão. Revista Brasileira de Psiquiatria, São Paulo, v. 30, n. 2, p. I56-167, jun. 2008.

ALVES, J. C. O desinteresse pela educação física escolar e a postura do educador físico. In: FÓRUM INTERNACIONAL DE ESPORTES, 6., Florianópolis, 2007. Anais... Florianópolis: UNESPORTE, 2007.

ANDERSON F; ANNETT M.; BISCHOF W. F. Lean on wii on: physical rehabilitation with virtual reality wii peripherals. Studies in Health Technology and Informatics, Amsterdan, v. I 54, p. 229-234, 2010.

AZEVEDO, V. A. "Press start": possibilidades educativas dos jogos eletrônicos. Trabalho de Conclusão de Curso (Graduação) - Centro de Desportos, Universidade Federal de Santa Catarina, Florianópolis, 2008.

.; PIRES, G. L.; SILVA, A. P. S. Jogos eletrônicos e suas possibilidades educativas. Motrivivência, Santa Catarina, ano 19, n. 28, p. 90- I00, jul. 2007.

BABIN, P.; KOULOMDJIAN, M. Os novos modos de compreender: a geração do audiovisual e do computador. São Paulo: Paulinas, 1989.

BETTI, M. A janela de vidro: esporte, televisão e educação física. 1997. 279 f. Tese (Doutorado) - Faculdade de Educação, Universidade Estadual de Campinas, Campinas, 1997.

BRAGA, M. Realidade virtual e educação. Revista de Biologia e Ciências da Terra, Paraíba, v. I, n. I, jan./jun. 200 I.

CARELLI, G. O campeão do lazer. Veja. São Paulo, p. 92, 26 nov. 2003.

COSTA, A. Q.; BETTI, M. Mídias e jogos: do virtual para uma experiência corporal educativa. Revista Brasileira de Ciências do Esporte, Campinas, v. 27, n. 2, p. I65- 178, jan. 2006.

DALEY A. J. Can exergaming contribute to improving physical activity levels and health outcomes in children? Pediatrics, Elk Grove Village, v. 124, n. 2, p. 763-77I, ago. 2010.

DEUTSCH J. E. et al. Use of a low-cost, commercially available gaming console (Wii) for rehabilitation of an adolescent with cerebral palsy. Physical Therapy, Alexandria, v. 88, n. I0, p. I196-1207, out. 2008. 
FERES NETO, A. A virtualização do esporte e suas novas vivências eletrônicas. 200 I . I I 7 f. Tese (Doutorado em Educação) - Faculdade de Educação, Universidade Estadual de Campinas, Campinas, 2001.

- Estaríamos caminhando para uma implosão do espaço-tempo e para a desrealização? Algumas implicações das teorias de Jean Baudrillard e Paul Virilio sobre o virtual para a educação/educação física. Lecturas Educación Física y Deportes, Buenos Aires, v. 64, 2003. Disponível em: <http://www.efdeportes.com/efd64/virtual.htm>. Acesso em: 09 jun. 2009.

Videogame e educação física/ciências do esporte: uma abordagem à luz das teorias sobre o virtual. EF Deportes: revista digital, Buenos Aires, v. I 0, n. 88, 2005. Disponível em: <http://www.efdeportes.com/efd88/video.htm>. Acesso em 09 jun. 2009.

- Videogame e educação física/ciências do esporte: uma abordagem à luz das teorias do virtual. In: CONGRESSO INTERNACIONAL DE CIÊNCIAS DO ESPORTE, 2.; CONGRESSO BRASILEIRO DE CIÊNCIAS DO ESPORTE, I 5., Recife, 2007. Anais... Goiânia: Colégio Brasileiro de Ciências do Esporte, 2007.

GEE, P. Bons videogames e boa aprendizagem. Perspectiva, Florianópolis, v. 27, n. I , p. I6778, jan./jun. 2009.

GRAVES, L. E. et al. The physiological cost and enjoyment of Wii Fit in adolescents, young adults, and older adults. Journal of Physical Activity \& Health, Champaign, v.7, n. 3, p. 393401 , may 2010.

KENSKI, V. M. O impacto da mídia e das novas tecnologias de comunicação na educação física. Motriz: revista de educação física, Rio Claro, v. I , n. 2, p. I29-133, dez. 1995.

LANNINGHAM-FOSTER, L. et al. Activity-promoting video games and increased energy expenditure. Journal of Pediatrics, Saint Louis, v. I54 n. 6, p. 819-823, jun. 2009.

LEMOS, A. Cibercultura: tecnologia e vida social na cultura contemporânea. Porto Alegre, Sulina, 2002.

LÉVY, P. O que é o virtual. São Paulo: Editora 34, 1996.

LÉVY, P. Cibercultura. Rio de Janeiro: Editora 34, 1999.

MARTINS, D. M.; COUTO JUNIOR, D. R. Jovens jogadores de videogames e produção de sentidos: contribuições para se pensar práticas educativas alteritárias. In: REUNIÃO ANUAL INTERNACIONAL DA ASSOCIAÇÃO DE PÓS-GRADUAÇÃO E PESQUISA EM EDUCAÇÃO: PESQUISA E COMPROMISSO SOCIAL, 30., Caxambú, 2007. Anais... 
Timbaúba: Espaço Livro, 2007. Disponível em: <http://www.anped.org.br/reunioes/30ra/ posteres/GT 16-3380--Int.pdf> Acesso em: I 5jun. 2009.

MIYACHI, M. et al. METs in adults while playing active video games: a metabolic chamber study. Medicine and Science in Sports and Exercise, Hagerstown v. 42, n. 6, p. I | 49- I I 53, jun. 2010.

MOITA, F. M. G. S. C. Jogos eletrônicos, juventude e currículo cultural: impulsionando uma nova prática educativa popular. In: REUNIÃO ANUAL DA ASSOCIAÇÃO DE PÓS-GRADUAÇÃO E PESQUISA EM EDUCAÇÃO: SOCIEDADE, DEMOCRACIA E EDUCAÇÃO, 27., Caxambu, 2004. Anais... Rio de Janeiro: Vozes, 2004. v. I.

Game on: jogos eletrônicos na escola e na vida da geração @. Campinas:

Alínea, 2007a.

Jogos eletrônicos: contexto cultural, curricular juvenil de "saber de experiência feito". In: REUNIÃO ANUAL INTERNACIONAL DA ASSOCIAÇÃO DE PÓS-GRADUAÇÃO E PESQUISA EM EDUCAÇÃO: PESQUISA E COMPROMISSO SOCIAL, 30., Caxambú, 2007. Anais... Timbaúba: Espaço Livro, 2007b. Disponível em: <http://mww. anped.org.br/reunioes/30ra/posteres/GT I6-3380--Int.pdf> Acesso em: I 5 jun. 2009.

; SILVA, A. C. R. Os games no contexto de currículo e aprendizagens colaborativas on-line. In: II COLÓQUIO LUSO-BRASILEIRO SOBRE QUESTÕES CURRICULARES: GLOBALIZAÇÃO E (DES)IGUALDADES: OS DESAFIOS CURRICULARES., 2., Braga, 2006. Anais... Braga: UNIMINHO, 2006. v. I . p. 50-65.

NITZ, J. C. et al. Is the wii fit a new-generation tool for improving balance, health and wellbeing? a pilot study. Climacteric: the journal of the International Menopause Society, Cornwall, v. |3, n. 5, p. 487-49|, out. 2010.

RAMOS, D. K. A escola frente ao fenômeno dos jogos eletrônicos: aspectos morais e éticos. Revista Novas Tecnologias na Educação, Porto Alegre, v. 6, n. I , jul. 2008.

REIS, L. J. A.; CAVICHIOLLI, F. R. Lazer à laser: os jogos eletrônicos no século XXI. In: SEMINÁRIO O LAZER EM DEBATE,9., São Paulo, 2008. Anais... São Paulo: Plêiade, 2008.

RIVOLTELLA, P. C. A formação da consciência civil entre o "real" e o "virtual" In: FANTIN, M.; GIRARDELLO, G. (Org.). Liga, roda, clica: estudos em mídia, cultura e infância. Campinas: Papirus, 2008. p. 4 I-56.

ROSADO, J. R. História do jogo e o game na aprendizagem. In: SEMINÁRIO JOGOS ELETRÔNICOS, EDUCAÇÃO E COMUNICAÇÃO: CONSTRUINDO NOVAS TRILHAS, 2., Salvador, 2006. Anais... Salvador: UNEB, 2006.

SILVA, F. V.; TORRES, J. M. Avaliação da utilização em sala de aula de um quadro digital interactivo baseado no wiimote. Revista da Faculdade de Ciência e Tecnologia, Porto, v. 6, p. 34-45, 2009. 
SPARKS D.; CHASE D.; COUGHLIN L. Wii have a problem: a review of self-reported Wii related injuries. Informatics in Primary Care, Milton Keynes, v. I7, n. I, p. 55-57, 2009. VAGHETTI, C. A. O.; BOTELHO, S. S. C. Ambientes virtuais de aprendizagem na Educação Física: uma revisão sobre a utilização de exergames. Ciências \& Cognição, Rio de Janeiro, v. I5, n. I, p. 76-88, abr. 2010.

Recebido: 28 out. 2010 Aprovado: 17 fev. 201 I

Endereço para correspondência: Fernando Joaquim Gripp Lopes Rua Adaléa Lessa Andrade, 60. Bairro Santo Inácio Diamantina-MG CEP: $39100-000$ 